\title{
INTERACTION BETWEEN THIN FILMS OF ZINC AND (100) GaAs*
}

\author{
E. KamińsKa, A. Piotrowska, R. Żarecka \\ Institute of Electron Technology, Al. Lotników 32/46, 02-668 Warszawa, Poland \\ AND E. MizERA \\ Institute of Physics, Polish Academy of Sciences \\ Al. Lotników 32/46, 02-668 Warszawa, Poland
}

\begin{abstract}
Interfacial reactions between thin films of $\mathrm{Zn}$ and $\mathrm{GaAs}$ were studied by means of transmission electron microscopy. Low-temperature interaction is governed by the penetration of $\mathrm{Zn}$ into the native oxide layer at the metal/GaAs interface. At $360^{\circ} \mathrm{C}$ the formation of $\mathrm{Zn}_{3} \mathrm{As}_{2}$ phase, highly oriented with respect to the (100) substrate takes place.
\end{abstract}

PACS numbers: $73.40 . \mathrm{Ns}$

Zinc is currently being used as a dopant element in ohmic contact metallization systems to $p$-type GaAs. The results of our recent studies on interfacial reactions occurring during formation of $\mathrm{Au}(\mathrm{Zn}) / p$-GaAs ohmic contact indicate that $\mathrm{Zn}$ plays a more universal role facilitating the dispersion of the native oxide on GaAs [1]. On the other hand, in plating and soldering technologies zinc is widely used as a component enabling one the cleaning of metallic surfaces before further processing $[2,3]$. To our knowledge, the precise mechanism of these "cleaning action" of zinc has not been yet established.

The aim of the present work is to elucidate the metallurgical behavior of $\mathrm{Zn}$ in contact with GaAs. The microstructural analysis of the $\mathrm{Zn} / \mathrm{GaAs}$ interface, under as-deposited state and annealed conditions, was carried out by transmission electron microscopy (TEM) methods. Emphasis was placed on the determination of the structure and composition of reaction products. High resolution electron microscopy (HREM) images were recorded with the JEOL JEM 2000EX (200 keV).

The substrates used in this study were (100) oriented $p$-type GaAs wafers doped with $\mathrm{Zn}$ to a concentration of $8 \times 10^{17} \mathrm{~cm}^{-3}$. Prior to metal deposition the samples were degreased in trichloroethylene (TCE), acetone and isopropyl alcohol, and then etched in solution of $\mathrm{NH}_{4} \mathrm{OH}: \mathrm{II}_{2} \mathrm{O}_{2}: \mathrm{II}_{2} \mathrm{O}$ (20:7:973), followed by a rinse in deionized $\mathrm{H}_{2} \mathrm{O}$ and immersion into $\mathrm{NH}_{4} \mathrm{OH}: \mathrm{H}_{2} \mathrm{O}(1: 10)$ for $10 \mathrm{~s}$. Zinc films, $150 \mathrm{~nm}$ thick, were deposited by vacuum thermal evaporation using $99.999 \% \mathrm{Zn}$ source, in

\footnotetext{
*This work was supported by the grant No. 8-8026-92-03 of the Committee for Scientific Research.
} 
a system with a base pressure of $1 \times 10^{-7}$ Torr, at a rate $0.05 \mathrm{~nm} / \mathrm{s}$. To prevent the sublimation of $\mathrm{Zn}$ and As from the contact region the samples were capped with $200 \mathrm{~nm}$ thick rf-magnetron-sputtered $\mathrm{SiO}_{2}$ before annealing. IIeat treatments were performed in flowing $\mathrm{H}_{2}$ at temperatures ranging from 200 to $360^{\circ} \mathrm{C}$ for $10 \mathrm{~min}$. Cross-sectional TEM specimens were prepared by mechanical polishing, dimpling and ion milling.

The microstructure of the as-deposited $\mathrm{Zn} / \mathrm{GaAs}$ contact is shown in Fig. 1a. $\mathrm{Zn}$ films are crystalline in nature and consist of grains of $150-200 \mathrm{~nm}$ in size,

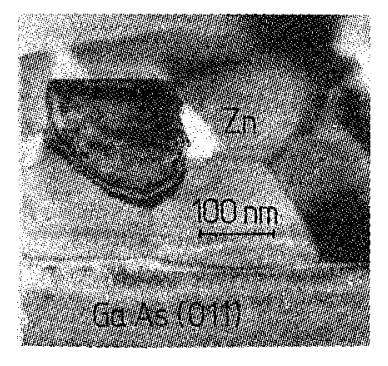

$\mathbf{a}$

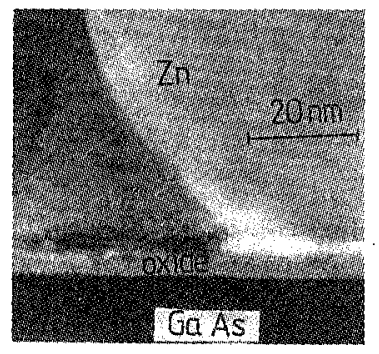

b

Fig. 1. (011) TEM micrographs of (a) as-deposited $\mathrm{Zn} / \mathrm{GaAs}$ contact, (b) as-deposited $\mathrm{Zn}$ /anodic oxide/GaAs contact.

strongly textured, with the orientation relationship: $(2 \overline{1} \overline{1} 0)_{\mathrm{Zn}} \|(011)_{\mathrm{GaAs}}$ and $[0001]_{\mathrm{Zn}} \|[100]_{\mathrm{GaAs}}$. This orientation relationship was preserved upon annealing up to around $320^{\circ} \mathrm{C}$.

The most significant feature of the low-temperature interaction of $\mathrm{Zn}$ with GaAs, which occurs during deposition and/or preparation of TEM specimens (about $100^{\circ} \mathrm{C}$ ) is the penetration of $\mathrm{Zn}$ into the residual oxide remaining at the surface of GaAs after etching. Such a native oxide layer (1-1.5 nm thick) is aiways present under conventional processing conditions which involve exposure of the GaAs surface to air prior to metal deposition.

To get further insight into the interaction of $\mathrm{Zn}$ with oxides, an attempt was made to deliberately incorporate about $10 \mathrm{~nm}$ thick oxide layer, by anodic oxidation of GaAs surface before depositing Zn (Fig. 1b). High-resolution images of $\mathrm{Zn} / \mathrm{GaAs}$ and $\mathrm{Zn} /$ oxide/GaAs interfaces are presented in Fig. 2a and Fig. $2 \mathrm{~b}$. The interface between $\mathrm{Zn}$ and $\mathrm{GaAs}$ is abrupt and atomically flat. The cross-section micrograph of $\mathrm{Zn}$ /oxide/GaAs sample clearly demonstrates that $\mathrm{Zn}$ is a dominant moving species.

Zn shows no evidence of reaction with the semiconductor substrate during deposition and annealing up to about $320^{\circ} \mathrm{C}$. Annealing at $360^{\circ} \mathrm{C}$ for $10 \mathrm{~min}$ produced a noticeable change in the contact microstructure. A new cubic $\mathrm{Zn}_{3} \mathrm{As}_{2}$ phase with $a=1.182 \mathrm{~nm}$ was identified by electron diffraction. $\mathrm{Zn}_{3} \mathrm{As}_{2}$ is lattice matched to $\mathrm{GaAs}$ substrate, with epitaxial relationship $(011)_{\mathrm{Zn}_{3} \mathrm{As}_{2}} \|(011)_{\mathrm{GaAs}}$ and $[100]_{\mathrm{Zn}_{3} \mathrm{As}_{2}} \|[100]_{\mathrm{GaAs}}$. The corresponding high-resolution image and selective diffraction pattern are shown in Fig. 2c.

In summary, the low-temperature interaction between $\mathrm{Zn}$ and $\mathrm{GaAs}$ is gov- 


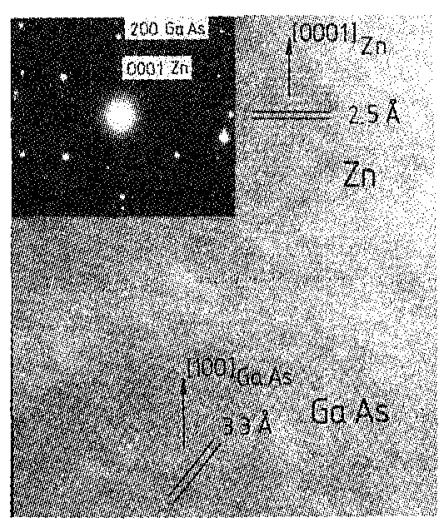

$\mathbf{a}$

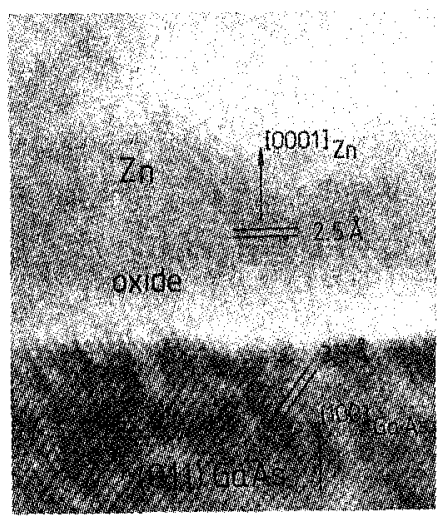

b

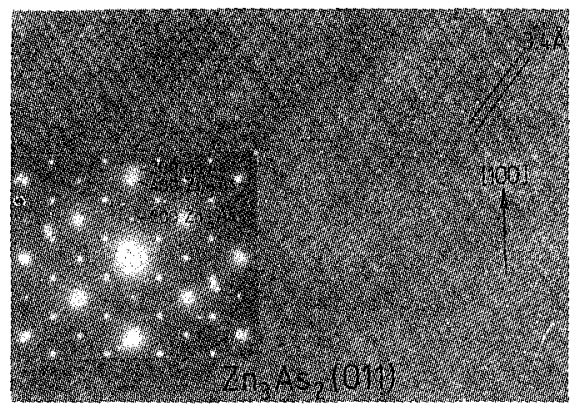

$\mathbf{3}$

Fig. 2. (011) HREM micrographs and corresponding SAD patterns of (a) as-deposited $\mathrm{Zn} / \mathrm{GaAs}$ contact, (b) as-deposited $\mathrm{Zn}$ /anodic oxide/GaAs contact, showing the penetration of $\mathrm{Zn}$ into the oxide, (c) $\mathrm{Zn}_{3}$ As 2 phase.

erned by the penetration of $\mathrm{Zn}$ into the native oxide layer. For this reason, metallization systems containing $\mathrm{Zn}$ such as $\mathrm{AuZn}$, react with GaAs in a more laterally uniform manner than pure Au.

\section{References}

[1] E. Kamińska, A. Piotrowska, R. Żarecka, A. Barcz, E. Mizera, S. Kwiatkowski, Acta Phys. Pol. A 82, 853 (1992).

[2] H.H. Manko, Solders and Soldering, McGraw-IIill, New York 1964.

[3] W.G. Zelley, in: Modern Electroplating, 2nd ed., Ed. F.A. Lowenheim, Wiley, New York 1963, p. 556. 